\title{
RELEVANSI KOMPETENSI LULUSAN SMK KHUSUSNYA KOMPETENSI KEAHLIAN TEKNIK GAMBAR BANGUNAN DENGAN KOMPETENSI YANG DIBUTUHKAN DI DUNIA KERJA
}

\author{
M. Agphin Ramadhan, Tuti Iriani dan Santoso Sri Handoyo
}

\begin{abstract}
The Objective of this study to determine the relevance of vocational high schools (SMK) graduates especially in drawing technique building (TGB) with competence is needed in the world of work. This research was conducted in the state vocational high schools (SMKN) in Jakarta who organized a program of TGB, they are SMKN 26, SMKN 35, SMKN 52, and SMKN 56, Jakarta, and in several companies of construction industry. The sample in this research a number of 40 people, they were graduated in 2010 and 2011. The research taken using a purposive sample techniques.

There are three instrument used. First, instrument competence graduates who votes by The Chairman of the TGB programs. This instrument is basic competence of curriculum (KTSP) SMK of TGB. Second, instrument competence required in the work hosted by graduates SMK of TGB by self assessment. Third, instrument competence required in the work hosted by manager to judge ability graduates SMK of TGB. Based on the research can be concluded that graduates SMK of TGB is competent in drawing, using software, and softskill. But in terms of counting, ability graduates SMK of TGB still low.
\end{abstract}

Keyword : competence, vocational high schools, drawing technique building, graduate, manager

\begin{tabular}{|l|c|r|}
\hline M. Agphin Ramadhan & Dr. Tuti Iriani, M.Si & Drs. Santoso Sri Handoyo, MT \\
Alumni Jurusan Teknik Sipil & Jurusan Teknik Sipil & Jurusan Teknik Sipil \\
Fakultas Teknik & Fakultas Teknik & Fakultas Teknik \\
Universitas Negeri & Universitas Negeri Jakarta,13220 & Universitas Negeri Jakarta, 13220 \\
Jakarta,13220 & email :t_iriani@yahoo.com & email:santoso_handoyo@yahoo.com \\
\hline
\end{tabular}




\section{PENDAHULUAN}

Perkembangan dunia kerja, dalam hal ini dunia industri jasa konstruksi, di DKI Jakarta berkembang sangat cepat. Hal ini ditandai dengan menjamurnya proyek-proyek pembangunan dan perusahaan-perusahaan yang baru berkembang di industri jasa konstruksi. Perkembangan yang cepat dalam dunia kerja menuntut antisipasi dan evaluasi terhadap kompetensi yang dibutuhkan oleh dunia kerja.

Dalam Kurikulum Sekolah Menengah Kejuruan Garis-Garis Besar Program Pendidikan dan Keahlian, SMK adalah salah satu bentuk usaha dalam mempersiapkan sumber daya manusia yang terampil melalui jalur formal. Pada SMK, proses belajar mengajar lebih ditekankan pada aspek psikomotorik yaitu dalam bentuk keterampilan. Hal ini didasari oleh tujuan pendidikan kejuruan itu sendiri, yaitu: "menyiapkan siswa untuk memasuki lapangan kerja serta mengembangkan sikap profesionalisme, menyiapkan siswa agar mampu memilih karir, mampu berkompetisi dan mampu mengembangkan diri, menyiapkan tenaga kerja tingkat menengah untuk mengisi kebutuhan dunia usaha dan industri pada saat ini maupun masa yang akan datang, menyiapkan tamatan agar menjadi warga negara yang produktif, normatif, dan adaptif' Murniati (2009).

Thomson (1974) dalam Jalinus (2011) menyatakan bahwa "vocational education is economic education as it geared to the needs of the job marked and thus contributed to the national economic growth". Pendidikan kejuruan pada dasarnya adalah pendidikan untuk menumbuhkan atau menggerakkan kegiatan ekonomi, karena pendidikan kejuruan dirancang untuk memenuhi kebutuhan pasar kerja dan jelaslah hal ini akan memberikan sumbangsih positif bagi dunia kerja produktif yang menghasilkan barang dan komoditi yang mempunyai nilai ekonomi.

Sedangkan kenyataannya, dalam mempersiapkan siswa SMK sebagai tenaga kerja tingkat menengah kerap ditemui adanya masalah. Permasalahan yang dihadapi diantaranya masih terdapat kesenjangan kompetensi lulusan SMK dengan kebutuhan riil pihak dunia usaha dan industri (Dit.PSMK, 2008).

Kesenjangan ini salah satunya dapat diindikasikan dengan rendahnya daya serap tenaga kerja lulusan SMK oleh dunia usaha atau industri (SARKERNAS, 2009). Kondisi tersebut cenderung mengakibatkan terjadinya pengangguran terbuka. Berdasarkan data Badan Pusat Statistik (BPS) Agustus 2011 pengangguran terbuka di Indonesia didominasi oleh lulusan SMA dan SMK. Dibanding kondisi di Februari 2011, tingkat pengangguran terbuka tertinggi adalah untuk masyarakat lulusan SMA dan SMK sebesar $10,66 \%$ dan $10,43 \%$.

Menurut Barliana (2011) dari sekian banyak jurusan di SMK, yang paling menarik untuk dikaji dan kemudian direvitalisasi adalah SMK Teknik Bangunan. Jika dibandingkan dengan SMK Teknik Mesin/ Otomotif atau Teknik Elektro/ Elektronika yang SMK-nya berkembang berbanding lurus dengan dunia industrinya, pertumbuhan SMK Teknik Bangunan justru 
berbanding terbalik dengan perkembangan industri konstruksi. Jumlah SMK Teknik Bangunan terus berguguran baik di sekolah negeri maupun di sekolah swasta, sedangkan dunia industri konstruksi sebagai lahan kerja sebagian besar lulusan SMK Teknik Bangunan terus tumbuh dan berkembang.

Dari 563 SMK di DKI Jakarta hanya ada 62 SMK Negeri, sedangkan sisanya adalah swasta. Dari 62 SMK Negeri tersebut lebih dari $50 \%$, yaitu sebanyak 34 sekolah memiliki program keahlian yang berhubungan dengan Ekonomi, seperti manajemen, akuntansi, pemasaran, dan lain sebagainya. Dari 62 SMK Negeri di Jakarta, hanya ada 26 SMK Negeri jurusan ketekenikan. Dan dari 26 SMK Negeri tersebut dibagi menjadi empat sekolah sesuai kriteria keteknikan, yaitu: Teknik Mesin, Teknik Elektro, IImu Kesejahteraan Keluarga (IKK), dan Teknik Bangunan. Tiga belas sekolah masuk ke dalam jurusan Teknik Mesin, dua belas sekolah masuk ke dalam jurusan Teknik Elektro dan IKK. Sedangkan untuk jurusan Teknik Bangunan hanya ada tujuh sekolah.

Barliana (2011) juga berpendapat bahwa salah satu persoalan sepinya peminat untuk memilih SMK Jurusan Teknik Bangunan, karena lulusan SMK Teknik Bangunan sering kali dianggap hanya akan menjadi kuli bangunan oleh masyarakat. Hal ini diperkuat dengan pernyataan yang tertera pada kurikulum 1993 yang secara implisit mengarahkan tamatan SMK Teknik Bangunan pada kualifikasi juru/ tukang bangunan.
Meskipun sejak kurikulum berbasis kompetensi (KBK) tahun 2004 sampai kurikulum tingkat satuan pendidikan (KTSP) tahun 2008 Standar Kompetensi SMK Bangunan, menjadi level kualifikasi "pelaksana" dan bukan "juru atau tukang", namun tampaknya usaha itu belum akan mengikis citra negatif tentang SMK Bangunan. Persoalannya adalah walaupun disebut pelaksana, sebagian besar level kompetensi dan spesifikasi keahlian bangunan baik pada Program Studi Keahlian Gambar Bangunan, Konstruksi Kayu, Kontruksi Baja, dan Finishing dapat dikerjakan oleh tenaga tukang bangunan yang tidak terdidik. Meskipun secara teoritik lemah, tapi umumnya keahlian dan kerja kerasnya akan jauh lebih baik dari pada tamatan SMK (Barliana, 2011).

Berdasarkan Lampiran Keputusan

Direktur Jendral Manajemen Pendidikan Pendidikan Dasar dan Menengah Nomor: 251/ C/ Kep/ MN/ 2008 tentang Spektrum Keahlian Pendidikan Menengah Kejuruan, Program Studi Keahlian Teknik Bangunan memiliki lima Kompetensi Keahlian, yaitu: Teknik Konstruksi Baja, Teknik Konstruksi Kayu, Teknik Konstruksi Batu dan Beton, Teknik Gambar Bangunan, dan Teknik Furnitur. Di DKI Jakarta terdapat tujuh SMK yang menyelenggarakan Program Studi Keahlian Teknik Bangunan, yaitu: SMKN 1, SMKN 4, SMKN 26, SMKN 35, SMKN 52, SMKN 56, dan SMKN 58. Dari masing-masing SMK tersebut dipisahkan menjadi empat kompetensi keahlian, yaitu: teknik konstruksi kayu, teknik konstruksi batu dan beton, teknik gambar bangunan, dan furnitur. 
Dalam penelitian ini akan difokuskan kepada kompetensi keahlian TGB yang merupakan kompetensi keahlian yang paling banyak diselenggarakan oleh SMK Teknik Bangunan di DKI Jakarta. Berdasarkan pemaparan di atas maka peneliti tertarik untuk meneliti tentang relevansi kompetensi lulusan SMK Program Studi Keahlian Teknik Bangunan dengan kompetensi yang dibutuhkan di dunia kerja pada Kompetensi Keahlian TGB

\section{Tinjauan Pustaka}

\section{Pengertian Kompetensi}

Surat Keputusan Mendiknas nomor 045/U/2002 tentang Kurikulum Inti Perguruan Tinggi mengemukakan "Kompetensi adalah seperangkat tindakan cerdas penuh tanggungjawab yang dimiliki seseorang sebagai syarat untuk dianggap mampu oleh masyarakat dalam melaksanakan tugas-tugas di bidang pekerjaan tertentu".

Kompetensi (competency) didefinisikan oleh Palan (2007) sebagai deskripsi mengenai perilaku. Secara lebih terperinci deskripsi itu merujuk kepada karakteristik yang mendasari perilaku yang menggambarkan motif, karakteristik pribadi (ciri khas), konsep diri, nilainilai, pengetahuan, atau keahlian. Dalam Kamus Besar Bahasa Indonesia (2008), kompetensi adalah kewenangan (kekuasaan) untuk menentukan atau memutuskan sesuatu hal. Menurut Finch dan Crunkilton dalam Mulyasa (2004) bahwa yang dimaksud dengan kompetensi adalah penguasaan terhadap suatu tugas, keterampilan sikap, dan apresiasi yang diperlukan untuk menunjang keberhasilan. Hal ini menunjukkan bahwa kompetensi mencakup tugas, keterampilan sikap dan apresiasi yang harus dimiliki peserta didik untuk dapat melaksanakan tugas-tugas pembelajaran sesuai dengan jenis pekerjaan tertentu.

Kompetensi menurut UU No.13/ 2003 tentang Ketenagakerjaan: pasal 1 (10) "Kompetensi adalah kemampuan kerja setiap individu yang mencakup aspek pengetahuan, keterampilan, dan sikap kerja yang sesuai dengan standar yang ditetapkan". Haryati (2007: 43) menjelaskan bahwa kompetensi merupakan pengetahuan (kognitif), sikap dan nilai-nilai (afektif) dan keterampilan (psikomotor) yang diwujudkan dalam kebiasaan berfikir dan bertindak sehingga mampu menghadapi persoalan yang dihadapinya.

Soeprijanto (2010) menjelaskan bahwa kompetensi bersifat kompleks dan merupakan satu kesatuan yang utuh yang menggambarkan potensi, pengetahuan, keterampilan, sikap dan nilai yang dimiliki seseorang yang terkait dengan profesi tertentu terutama berkenaan dengan bagian-bagian yang dapat diaktualisasikan atau diwujudkan dalam bentuk tindakan atau kinerja untuk menjalankan profesi tersebut. Potensi kompetensi belum ditunjukkan dalam prilaku nyata, tetapi merupakan persyaratan yang diyakini memberi jaminan bahwa individu yang memiliki kompetensi tersebut dapat menunjukkan kinerja yang unggul. 
Dari definisi di atas kompetensi dapat digambarkan sebagai kemampuan untuk melaksanakan satu tugas, kemampuan mengintegrasikan pengetahuan, keterampilan, sikap, dan nilai-nilai pribadi, dan kemampuan untuk membangun pengetahuan dan keterampilan yang didasarkan pada pengalaman dan pembelajaran yang dilakukan.

\section{Kompetensi Lulusan}

Berdasarkan UU No 20/ 2003 tentang Sisdiknas penjelasan pasal 35 (1), kompetensi lulusan merupakan kualifikasi kemampuan lulusan yang mencakup sikap, pengetahuan, dan keterampilan sesuai dengan standar nasional yang telah disepakati. Depdiknas (2007) menyatakan bahwa kompetensi lulusan adalah kualifikasi kemampuan lulusan yang mencakup sikap, pengetahuan, dan keterampilan.

Wahyuningsih (1996) menyatakan bahwa kompetensi lulusan adalah sanggup melakukan pekerjaan pada industri sesuai dengan kemampuan sendiri sebagai tenaga menengah terampil dalam dunia industri. Sedangkan Shadan (2008: 13) mengatakan bahwa kompetensi lulusan adalah semua kombinasi pengetahuan, keterampilan, keahlian yang diperoleh mahasiswa dari awal hingga dia lulus dari perguruan tinggi.

Dengan demikian dapat disimpulkan bahwa kompetensi lulusan adalah kemampuan yang mencakup sikap, pengetahuan, keterampilan, dan keahian yang dimiliki seseorang yang telah melalui proses pendidikan yang dilakukan oleh sebuah lembaga pendidikan.
Kompetensi siswa SMK pada prinsipnya mengacu kepada sandar kompetensi yang dituntut oleh industri yang sesuai dengan bidang keahliannya masing-masing. Namun dengan industri yang beragam dan memiliki karakteristik yang berbeda-beda,maka ditetapkanlah standar kompetensi yang dijabarkan langsung dalam Standar Kompetensi Lulusan (SKL).

Peraturan Pemerintah No.19 Tahun 2005 tentang Standar Nasional Pendidikan mendeskripsikan SKL sebagai berikut:

a. Standar kompetensi lulusan digunakan sebagai pedoman penilaian dalam penentuan kelulusan peserta didik, yang meliputi kompetensi untuk seluruh mata pelajaran, serta mencakup aspek sikap, pengetahuan, dan keterampilan.

b. Standar kompetensi lulusan pada pendidikan menengah bertujuan untuk meningkatkan kecerdasan, pengetahuan, kepribadian, akhlak mulia, dan keterampilan untuk hidup mandiri dan mengikuti pendidikan lebih lanjut sesuai dengan keahliannya.

\section{Standar Kompetensi SMK Program Studi Keahlian Teknik Bangunan Kompetensi Keahlian TGB}

Secara umum Standar Kompetensi (SK) Kompetensi Keahlian TGB yang digunakan sebagai acuan pengembangan kurikulum saat ini adalah Standar Kompetensi Kerja Nasional Indonesia (SKKNI). Adapun SK Kompetensi Keahlian TGB berdasarkan Spektrum Kurikulum 
SMK 2008 Kompetensi Keahlian TGB adalah sebagai berikut:

1. Mengatur tata letak gambar manual

2. Menggambar dengan perangkat lunak

3. Membuat gambar rencana kolom beton bertulang

4. Membuat gambar rencana balok beton bertulang

5. Menggambar konstruksi lantai dan dinding bangunan

6. Menggambar rencana dinding penahan

7. Menggambar konstruksi kusen, pintu dan jendela

8. Menggambar rencana plat lantai

9. Menggambar konstruksi tangga

10. Menggambar konstruksi langit-langit

11. Menggambar konstruksi atap

12. Menggambar utilitas gedung

13. Menggambar lay out dekorasi interior dan eksterior

14. Menggambar dekorasi interior rumah tinggal, perkantoran dan ruang publik

15. Menerapkan desain interior bangunan

16. Menentukan unsur penunjang desain interior dan eksterior bangunan

17. Menerapkan desain eksterior bangunan

18. Menerapkan material finishing bangunan

19. Merancang partisi ruang

\section{Kompetensi Keahlian Teknik Gambar}

\section{Bangunan}

Pendidikan mempunyai peran yang sangat strategis dalam meningkatkan kualitas sumber daya manusia dan upaya mewujudkan cita-cita bangsa Indonesia dalam mewujudkan kesejahteraan umum dan mencerdaskan kehidupan bangsa. Pemerintah merumuskan dalam Undang-Undang Republik Indonesia No 20 tahun 2003 tentang Sistem Pendidikan Nasional yang menjelaskan bahwa pendidikan dilakukan agar mendapatkan tujuan yang diharapkan bersama yaitu:

"Pendidikan nasional berfungsi
mengembangkan kemampuan dan
membentuk watak serta peradaban
bangsa yang bermartabat dalam rangka
mencerdaskan kehidupan bangsa,
bertujuan untuk berkembangnya potensi
peserta didik agar menjadi manusia yang
beriman dan bertakwa kepada Tuhan
Yang Maha Esa, berakhlak mulia, sehat,
berilmu, cakap, kreatif, mandiri, dan
menjadi warga negara yang demokratis
serta bertanggung jawab" (Pasal 3 UU RI
No 20/ 2003).
Dengan demikian, jelaslah pendidikan merupakan kegiatan yang dilakukan dengan sengaja agar anak didik memiliki sikap dan kepribadian yang baik, sehingga penerapan pendidikan harus diselengggarakan sesuai dengan Sistem Pendidikan Nasional berdasarkan UU No 20/ 2003. Menurut UU RI No 20/ 2003 tentang Sistem Pendidikan Nasional jenis dari pendidikan menengah salah satunya adalah SMK. Penjelasan pasal 15 menjelaskan bahwa "Pendidikan kejuruan merupakan pendidikan menengah yang mempersiapkan peserta diklat terutama untuk bekerja dalam bidang tertentu".

SMK di Indonesia tersurat dalam UndangUndang Nomor 20 tahun 2003 tentang Sistem Pendidikan Nasional (Sisdiknas) pasal 18 ayat 2 dan 3. SMK merupakan bagian dari pendidikan 
menengah yang ada di Indonesia selain Sekolah Menengah Umum (SMU). SMK adalah sekolah menengah yang menyelenggarakan pendidikan kejuruan dengan mengutamakan penyiapan siswa untuk memasuki lapangan kerja serta mengembangkan sikap profesional.

SMK Program Studi Keahlian Teknik Bangunan merupakan salah satu dari program studi bidang keahian teknologi dan rekayasa. Berdasarkan Lampiran Keputusan Direktur Jendral Manajemen Pendidikan Pendidikan Dasar dan Menengah Nomor: 251/ C/ Kep/ MN/ 2008 tentang Spektrum Keahlian Pendidikan Menengah Kejuruan, Program Studi Keahlian Teknik Bangunan memiliki lima Kompetensi Keahlian, yaitu: Teknik Konstruksi Baja, Teknik Konstruksi Kayu, Teknik Konstruksi Batu dan Beton, Teknik Gambar Bangunan, dan Teknik Furnitur.

Mengacu pada isi Undang Undang Sistem Pendidikan Nasional (UU SPN) pasal 3 mengenai Tujuan Pendidikan Nasional dan penjelasan pasal 15 yang menyebutkan bahwa pendidikan kejuruan merupakan pendidikan menengah yang mempersiapkan peserta didik terutama untuk bekerja dalam bidang tertentu. Secara khusus tujuan Kompetensi Keahlian TGB merupakan program keahlian yang didesain untuk menghasilkan tenaga muda yang terampil dalam mendesain, merencana, menghitung nilai suatu bangunan, dan pada akhirnya mampu menghasilkan produk yaitu dokumen perencanan konstruksi suatu bangunan. Dengan kata lain lulusan dari SMK Kompetensi Keahlian TGB disiapkan untuk menjadi seorang drafter muda.
Drafter muda yang merupakan jenjang kualifikasi pertama di dalam dunia profesi juru gambar ini adalah juru gambar dengan pemahaman perangkat lunak menggambar teknik (AutoCAD atau sejenisnya) dan memiliki kemampuan menggambar dengan cepat sesuai draft dan bertanggung jawab dengan baik pada pekerjaannya serta mampu bekerjasama. (Pengantar Standar Kompetensi Nasional Bidang Gambar Bangunan: 2003)

\section{METODE PENELITIAN}

Metode penelitian yang akan dilakukan yaitu melalui pendekatan kuantitatif dengan jenis penelitian deskriptif. Angket berisi pertanyaan untuk mengetahui kompetensi lulusan SMK TGB terhadap kompetensi yang dibutuhkan di dunia kerja. Data pada kompetensi lulusan SMK TGB diambil dari angket yang diisi oleh Kepala Program Keahlian TGB di masing-masing sekolah. Sedangkan data pada kompetensi lulusan SMK terhadap kompetensi yang dibutuhkan di dunia kerja diambil dari angket yang diisi oleh lulusan SMK TGB dengan melakukan penilaian diri (self assesment) dan manajer/ atasan yang menilai kemampuan lulusan SMK TGB.

\section{HASIL PENELITIAN}

Berdasarkan perhitungan data tentang kompetensi yang dibutuhkan di dunia kerja diketahui bahwa:

a. Nilai rerata indikator menggambar (3,03 dan 3,06) menunjukkan kompetensi lulusan SMK TGB sudah cukup kompeten. Hal ini 
juga ditunjukkan pada sub inidikator membuat gambar pelaksanaan/ shop drawing (3,2 dan 3,22) dan gambar akhir pekerjaan/ as built drawing $(3,17$ dan 3,25). Sedangkan pada sub indikator membuat gambar rencana konstruksi bangunan (2,9 dan 2,9) dan non konstruksi bangunan (2,85 dan 2,88), kemampuan lulusan masih rendah.

b. Nilai rerata indikator menggunakan software (2,74 dan 2,76) menunjukkan kompetensi Iulusan SMK TGB terbilang rendah. Hal ini juga ditunjukkan pada sub inidikator software pendukung gambar (2,6 dan 2,65) dan software perhitungan struktur (1,8 dan 1,85). Sedangkan pada sub indikator software AutoCAD (3,1 dan 3,12) dan software Ms.Office (3,47 dan 3,42), kemampuan lulusan cukup kompeten.

c. Nilai rerata indikator menghitung $(2,72$ dan 2,71) menunjukkan kompetensi lulusan SMK TGB terbilang rendah. Hal ini juga ditunjukkan pada sub indikator menghitung kebutuhan material (2,89 dan 2,86), anggaran bangunan (2,71 dan 2,76) dan, statika bangunan (2,57 dan 2,52).

d. Nilai rerata indikator softskill (3,0 dan 2,9) menunjukkan kompetensi lulusan SMK TGB sudah cukup kompeten. Hal ini juga ditunjukkan pada sub inidikator disiplin $(3,1$ dan 3,14$)$ dan presenting $(3,2$ dan 3,15$)$. Sedangkan pada sub indikator interpersonal (2,95 dan 2,87 dan) dan inisiatif (2,8 dan 2,91), kemampuan lulusan SMK TGB masih rendah.

\section{KESIMPULAN}

Berdasarkan deskripsi, analisis, dan interpretasi data yang telah diuraikan pada babbab sebelumnya, dapat ditarik kesimpulan bahwa kompetensi lulusan SMK Program Studi Keahlian Teknik Bangunan Kompetensi Keahlian TGB relevan dengan kompetensi yang dibutuhkan di dunia kerja.

Pada kompetensi menggambar, lulusan SMK TGB sudah kompeten dalam membuat gambar pelaksanaan/ shop drawing dan gambar akhir pekerjaan/ as built drawing. Pada kompetensi menggunakan software, lulusan SMK TGB kompeten dalam mengoperasikan software AUTOCAD dan Ms.Office. Namun kurang kompeten dalam mengoperasikan software pendukung gambar seperti: 3dmax, photoshop, corel draw dan sebagainya serta software perhitungan struktur. Sedangkan pada kompetensi menghitung, lulusan SMK TGB tidak kompeten, baik dalam hal kebutuhan material, anggaran bangunan, dan konsep perhitungan statika bangunan. Selanjutnya dalam hal softskill, lulusan SMK TGB sudah memiliki sikap disiplin dan mampu menjelaskan (presenting). Namun dalam hal menjalin relasi dengan orang lain (interpersonal) dan inisiatif kemampuan lulusan SMK TGB masih harus ditingkatkan.

\section{SARAN}

Berdasarkan kesimpulan di atas dapat dikemukakan saran-saran sebagai berikut:

a) Kompetensi menggambar siswa SMK Teknik Gambar Bangunan kurang 
maksimal, khususnya menggambar rencana konstruksi dan non konstruksi bangunan. Sebaiknya dalam proses pembelajaran di sekolah lebih ditekankan pada menggambar rencana. Agar saat terjun ke dunia kerja, lulusan SMK Teknik Gambar Bangunan memiliki kompetensi menggambar yang baik.

b) Sekolah dalam hal ini SMK Teknik Gambar Bangunan sudah dapat mencetak lulusan-lulusan yang handal dalam mengoperasikan software AUTOCAD. Namun sebaiknya juga diberikan pelajaran tambahan mengenai software pendukung gambar, seperti: 3dmax, photoshop, corel draw, dan sebagainya.

c) Siswa SMK Teknik Gambar Bangunan sebaiknya meningkatkan kompetensi menghitung. Karena berdasarkan pengolahan data, kompetensi menghitung merupakan yang paling rendah dikuasai oleh lulusan. Hal ini tidak hanya menjadi tugas siswa, tetapi juga menjadi tugas guru untuk memberikan pembelajaran yang menarik sehingga siswa SMK dapat memahami pelajaran yang berkaitan dengan menghitung dengan baik. Sehingga saat lulus dan bekerja, lulusan SMK Teknik Gambar Bangunan mampu menghitung anggaran bangunan dan kebutuhan material.

d) SMK sebaiknya mengadakan program sekolah yang dapat meningkatkan softskill peserta didik. Dengan cara mengadakan sistem PKL (Praktek Kerja
Lapangan) atau Prakerin (Praktek Kerja Industri) yang profesional. Sehingga saat lulus dan bekerja, lulusan SMK Teknik Gambar Bangunan siap terjun di dunia kerja dan memiliki softskill yang baik.

\section{DAFTAR PUSTAKA}

A.R, Murniati \& Nasir, Usman. 2009. Implementasi Manajemen Stratejik Dalam Pemberdayaan Sekolah Menengah Kejuruan.

Arikunto S. 2006. Prosedur Penelitian Suatu Pendekatan Praktik. Jakarta : Rineka Cipta.

Haryati, Mimin. 2007. Model \& Teknik Penilaian pada Tingkat Satuan Pendidikan. Jakarta: GP Press

Jurnal Penelitian Pendidikan Vol.9 Tahun ke 3 Desember 2010. Fakhri, Edi. 2010. Relevansi Kompetensi dan Tingkat Daya Saing Lulusan SMK Dalam Dunia Kerja. Padang: UNP

Jurnal Pendidikan Vokasi Vol.3 No.1 Februari 2011. Jalinus, Nizwardi. 2011. Pengembangan Pendidikan Teknologi dan Kejuruan dan Hubungan Dunia Kerja. Yogyakarta: UNY

Klaus, Peggy. 2012. Jangan Anggap Sepele Soft skills, Keterampilan yang Dipraktikkan Orang Cerdas di Tempat Kerja. Jakarta: Libri

LPPM-ITB. 2003. Buku I Pengantar Standar Kompetensi Nasional Bidang Gambar Bangunan. Bandung: tidak diterbitkan

Reitz, Joan M. 2004. Dictionary for Library and Information Science. Wetsport CT: Libraries Unlimited

Riduwan. 2008. Metode \& Teknik Menyusun Tesis. Bandung: Alfabeta 
Shadan. 2008. Studi Kompetensi Drafter Pada Lulusan Jurusan Pendidikan Teknik Sipil Fakultas Teknik Universitas Negeri Jakarta. Skripsi. Jakarta: UNJ

Soeprijanto. 2010. Pengukuran Kinerja Guru Praktik Kejuruan Konsep dan Teknik Pengembangan Instrumen. Jakarta: CV. Tursina

Sugiyono. 2010. Metode Penelitian Pendidikan. Bandung: Alfabeta

Sugono, Dendy. 2008. Kamus Bahasa Indonesia Pusat Bahasa Departemen Pendidikan Nasional. Jakarta: Departemen Pendidikan Nasional

Tarra, Yulberti. 2011. Kajian Kesesuaian Kurikulum Tingkat Satuan Pendidikan Pada Kompetensi Keahlian Teknik Gambar Bangunan SMK Negeri 6 Bandung Dengan Kebutuhan Dunia Industri. Skripsi. Bandung: UPI

Teriska. 2012. Internalisasi Softskills Melalui Diklat PAKEM dalam Rangka Meningkatkan Mutu Pendidikan. Skripsi. Bandung: UPI

Tim Pengembang IImu Pendidikan FIP UPI. 2007. IImu dan Aplikasi Pendidikan. Edisi 2. Bandung: PT. IMTIMA
Barliana, Syaom. 2010. Paradok SMK Bangunan. file.upi.edu/Direktori/FPTK/JUR.../Parado ks_SMK.pdf. Diakses pada tanggal 5 November 2011.

Direktorat Pembinaan SMK. 2008. Lampiran Keputusan Dirjen Manajemen Pendidikan Dasar dan Menengah. http://www.ditpsmk.net/?page=news;Nzk3 - Diakses pada tanggal 27 November 2011.

Ditpertais. 2004. Kurikulum Berbasis Kompetensi.

http://www.ditpertais.net/swara/warta1703.asp. Diakses pada tanggal 27 November 2011.

Runiasari. 2011. Angka Pengangguran Terbuka Menurun.

http://www.suaramerdeka.com/v1/index.p hp/read/news/2011/11/07/101184/AngkaPengangguran-Terbuka-Menurun.

Diakses pada tanggal 26 November 2011.

Undang-undang Republik Indonesia No.13 tahun 2003 Tentang ketenagakerjaan. www.pendidikan-

diy.go.id/file/uu/uu 13 2003.pdf. Diakses pada tanggal 27 November 2011 